to show some experiments on thermo-elasticity. The adiabatic thermal changes during extension and compression of materials have long been known, but measurement has been difficult. By employing a radiation thermopile and a galvanometer of high sensitivity and short period, the thermal effect of loading a specimen can be read on a scale, or recorded photographically, in a few seconds. The stresses in rigid materials can be measured with an accuracy comparable with any other known form of measurement, and strange to say, the order of the measurements depends on the coefficient of expansion of the material employed and not on Young's modulus and Poisson's ratio as in some other methods. Steel, brass, vulcanite and other bodies possessing a coefficient of expansion or contraction confirm this. In cases of plane complex stress, the measurements give the sum of the principal stresses. The adiabatic compression of various liquids, including water, has also been measured in this way, at pressures up to $1,500 \mathrm{lb}$. per sq. in., and the simple thermo-electrical arrangements used are such that the range of pressures can be extended almost indefinitely.

The Metropolitan-Vickers Electrical Company, Ltd., exhibited a portable noise-rneasuring apparatus, working on the aural balance principle. It consists essentially of a valve oscillator, a calibrated attenuator and a telephone earpiece. The oscillator generates current at 800 cycles which is fed to the telephone through adjustable attenuators. The apparatus is calibrated so as to indicate directly the intensity of the 800 cycle tone in the telephone in decibels above threshold of $0.0003 \mathrm{dynes} / \mathrm{sq}$. cm., measured in the ear or 0.00021 dynes/sq. cm., measured in free space. The observer places the telephone on one ear and presents the other to the complex noise to be measured. He then adjusts the attenuators until he judges the loudness of the 800 cycle note heard in the telephone to be equal to that of the complex noise. The equivalent value of the complex noise is then read in decibels above threshold from the settings of the attenuators.

A fractional seconds chronograph was shown by Mr. E. A. Nehan (Mathematical Department, Imperial College of Science). This instrument is designed to record visibly on paper tape, $0.01 \mathrm{sec}$. at $1 / 10$ th inch scale, up to four events simultaneously. A tuning fork controls a synchronous motor, which through a 3 -speed gear gives motion to a printing train and paper feed at the selected speed. Four inking pens record any event, translated as a simple make and break circuit, which mark on the tape is squared down to the time scale printed on the tape. The machine is portable, self-contained and worked from a 12-volt accumulator. Mr. J. Harvey, of the same Department, showed an integrator. By rolling a horizontal spur wheel on a rack in one direction and moving the rack perpendicularly, the axis of the wheel can be made to trace a curve whose Fourier coefficients are required. The wheel makes $n$ turns over a range of rack representing $0-2 \pi$. On a horizontal arm fixed to the axle of this wheel, is a wheel which rolls on the paper and registers the coefficients $a_{n}$ and $b_{n}$. Six harmonics can be found. The mechanism is adapted to find area, and first and second moments of area about an axis, on the principle of Amsler's moment integrator.

The National Physical Laboratory (Mr. R. A. Watson Watt, Mr. J. F. Herd and Mr. L. H. Bain. bridge-Bell) showed a cathode ray tube which has been made to serve as a magnetic compass. The cathode ray beam is deflected by the earth's magnetic field and may therefore be used as a compass needle free from inertia. In the present instrument light signals controlled by collector electrodes in the tube indicate any change in the magnetic bearing of the platform carrying the tube. Changes of a small fraction of a degree can be indicated. Among the exhibits by the Director of Scientific Research, Admiralty, was an apparatus which enables the deaf to hear by bone conduction. Amplified currents from a microphone are supplied to a coil wound direct on to a straight nickel iron wire which has a high magnetostriction coefficient. The wire vibrates with the frequency of the current and the vibrations may be transmitted to the cochlea through the bones of the head or jaw either by clenching the wire in the teeth or by pressing it on the mastoid bone behind the ear. The same Department also showed an automatic radio direction finder. This instrument is of the Bellini-Tosi type comprising two crossed frame coils and a goniometer, the search coil of which is rotated by an electric motor. The goniometer is connected to a radio receiver followed by a special rectifier and relay system which reverses the direction of the electric motor whenever the high frequency current in the search coil increases; thus, since the direction of rotation of the search coil is reversed whenever the minimum is passed, the search coil hunts a position at minimum.

\title{
Interpretation of Evidence for the Recession of Nebulæ
}

A

T Oxford on Tuesday, May 8, Dr. Edwin Hubble, of the Mount Wilson Observatory, delivered the Halley Lecture on "Red-Shifts in the Spectra of Nebulæ". As is indicated by the title, the lecture was concerned with a non-speculative account of those investigations, largely due to Dr. Hubble himself, which have led to the far-reaching speculations of de Sitter, Eddington, Milne, and others on the expansion of the universe. After a masterly account of the use of Cepheid variables in determining the distances of the nearer extra-galactic nebulæ, of the statistical methods involving the intrinsic luminosity of the average nebula for the distances of the remoter objects, and of the radial velocities or red-shifts measured by Slipher and Humason, Dr. Hubble developed in full the velocity-distance relation which bears his name. For the 150 nebulæ of which spectra have now been obtained, and which lie within a sphere of 150 million light years radius, he was able to show that the red-shifts, expressed as velocities, increase linearly by roughly one hundred miles per second for each million light years of distance; further, he was able to show that the difference between the linear relation for isolated nebulæ and for clusters of nebulæ is wholly the effect of selection, and thus to harmonise the results from all observed nebulæ.

The lecture concluded with an attempt to interpret the observed red-shift on the basis of the available observational material alone. If the red-shift is produced by some unspecified cause, Doppler effect being thus expressly excluded, then the brightness 
of the nebula will be reduced by the factor $(1-d \lambda / \lambda)$ because each quantum carries less energy, and also roughly by the same factor again because the weaker ultra-violet part of the spectrum is displaced into the photographic region (the correction from bolometric to photographic magnitude). If, on the other hand, the red-shift is due to an actual velocity of recession, then not only does each of the two previous effects reduce the brightness in the ratio $(1-d \lambda / \lambda)$, but also there is a reduction by a similar factor because the nebula is receding and fewer quanta reach the photographic plate per second. From counts of nebulæ made to five different apparent magnitudes, the numbers of nebulæ in each of the five corresponding spheres of increasing radius can be found, the radius of each sphere being given by the intrinsic luminosity of the average nebula and its apparent luminosity, corrected either by $(1-d \lambda / \lambda)$ for pure red-shift, or by $(1-d \lambda / \lambda)^{3}$ for red-shift interpreted as velocity of recession.

These counts indicate that, if the red-shift is due to velocity, then the number of nebulæ per unit volume must increase rapidly with increasing distance -a somewhat startling result; on the other hand, if the red-shift is not produced by a Doppler effect, then the counts indicate that the nebulæ are uniformly distributed over the sphere of 350 million light years radius which is within the range of the 100-inch reflector at Mount Wilson. While this particular result was not stressed by Dr. Hubble, he concluded by pointing out how the completion of the 200 -inch reflector will enable such counts and velocity determinations to be extended over a far larger volume of space, and will thus permit a definite interpretation of the red-shift, either as due to velocity of recession, or as due to some other yet unknown physical cause.

\section{Decrease of the Barn Owl in England and Wales}

$\mathrm{P}$

ECISE knowledge of the standing of particular birds in Britain should result from the increasing number of national censuses which have been initiated in recent years. Where the statistical information is thorough, it will form an invaluable basis of comparison with similar data gathered in future years; even where statistics have been dropped and reliance is placed upon the opinions of many observers scattered over a wide area, the consensus of opinion may still be a reliable guide to the fluctuations of the population.

Both kinds of information have been utilised in a census of the barn owl in England and Wales, made between May and December 1932, the results of which have been summarised by G. B. Blaker in an attractive pamphlet published by the Royal Society for the Protection of Birds. By making reasonable estimations in areas where direct information was not forthcoming, the author assesses the total breeding population of barn owls (Tyto alba) in England and Wales at 12,000 pairs. Non-breeding birds averaged one to every 50 square miles, so that the total adult population of barn owls in the summer of 1932 was about 25,000 individuals.

The absolute number is not so important as knowledge as to what relation it bears to that of former years, and here the statistics of one season, which contain no time element, cannot help. But putting one scrap of evidence regarding former conditions with another, Mr. Blaker has no difficulty in coming to the conclusion that the fears of those who suspected a serious decline in the numbers of the barn owl are justified. "From all districts in central and southern England the reports brought the same tale-fewer occupied nests than a few years ago. . . . In parts of Essex and Suffolk the decline was less marked, while in Devon and Cornwall the barn owl seems to be holding its own. Northumberland, Cumberland and Westmorland are the only counties to record an increase."

The decline in numbers over the greater part of the country appears to be no new thing : it has been noted for the last thirty or forty years. The disturbing point is that it has been speeding up during the last six years or so, until it has reached a point when, so far as the records can be interpreted, about four per cent of the population (or 1,000 birds) disappears annually; this, of course, over and above the annual wastage which would keep the population at a steady number.

Several factors contribute to the falling numbers of the barn owl. Nesting sites are fewer, partly because church authorities object to the occupation of towers and belfries by the ghostly 'cherubim', and fence the old nesting holes with wire entanglements; partly because modern barns with corrugated iron roofs do not offer openings like the 'owls' windows' of the old type. Food is probably more scarce since 'rat weeks' were instituted and the farmer has generally intensified his campaign against vermin. This has had a further effect in that the methods of destroying rats by poison has, the evidence indicates, resulted in the poisoning of owls which have devoured living but poisoned rats. Finally, there is the deliberate destruction of barn owls by people who should, but seemingly still do not, know better.

The author suggests, without definitely formulating the charge, that inefficiency of the Wild Birds Protection Acts is involved in the decline of the barnowl, but he states quite clearly the crux of this matter, namely, that it is in the administration of the law that the weakness, if any, lies. Were the critics of the present Birds Protection Acts to report the offences and insist with witnesses upon the prosecu. tion of the offenders (and they seem to be well supplied with instances of law-breaking), they would be making a contribution of value to the working of the law, and making no more of a contribution than the laws in question expect and make provision for them and other well-disposed citizens to make. But indeed, with regard to the barn owl, it is legitimate to ask whether the probability is that its present status would have been better or worse had there been no bird protection laws, and further why, if the law is a source of evil, the brown owl should have increased in numbers so enormously in the years when the barn owl has been declining ? J.R.

\section{University and Educational Intelligence}

Birmingham.-Mr. Stuart McDonald has been appointed lecturer in pathology in succession to Dr. F. W. M. Lamb, who has been appointed professor of forensic medicine at Cairo.

CAMbridge.-Dr. W. W. Watts has been appointed to represent the University at the centenary of the Edinburgh Geological Society on September 3-4. 